\title{
REFLEKSI PEMBELAJARAN APLIKASI MEDICAL WRITTING PRESENTATION PADA MAHASISWA SEMESTER SATU FAKULTAS KEDOKTERAN
}

\author{
Kevin Yulianto, Elisabeth Rukmini \\ Fakultas Kedokteran Universitas Katolik Atma Jaya Jakarta
}

\begin{abstract}
Background: Medical students need the ability to write and present research. Skills needed are referencing, using internet to help their research, and searching literatures through search engines. The lack of students' ability about searching a valid and reliable literature in the field of health and medicine according to EBM principle is a profound problem. Reflective thinking is also needed for the students to be able to reach meaningful learning. This study aimed to analyze the students' reflective writings within the Medical Writing Program.

Method: This research was a descriptive-explorative study using a qualitative approach. Subjects comprised 207 first semester medical students of Atma Jaya Catholic University of Indonesia batch 2012. Qualitative data were collected from students' written reflections about their learning experiences in MWP program. Qualitative analysis utilized content analysis included identification, coding, categorization, and synthesis.

Results: Students found that Zotero ${ }^{\oplus}$ was helpful as reference manager program in their writings. Zotero ${ }^{\circledR}$ Volunteer Troops also belped them in learning to use Zotero ${ }^{\circledR}$ and they felt more comfortable learning from their peers. EBM belped students searching and synthetizing literatures. Students also indirectly learned soft skills such as teamwork, time management, and speed reading in English (not their natives language).

Conclusion: Students had positive views of the program and its implementation. Students understood the importances of learning the MWP and felt that they could implement their studies directly in their academic careers.
\end{abstract}

KEYWORDS: early EBM; perception; reflection; medical writting; presentation

\begin{abstract}
ABSTRAK
Latar belakang: Mahasiswa kedokteran perlu memiliki keterampilan untuk dapat menulis dan mempresentasikan hasil penelitian, beberapa keterampilan tersebut antara lain kemampuan membuat bibliografi, menggunakan internet untuk membantu penelitian, dan mencari literatur dengan search engine. Masalah yang kini dihadapi adalah kurangnya kemampuan mahasiswa untuk mencari literatur di bidang kedokteran yang sahih dan dapat dipertanggungjawabkan menurut prinsip-prinsip EBM. Aspek reflective learning juga diperlukan bagi mahasiswa agar mendapatkan pembelajaran yang bermakna (meaningful learning). Penelitian ini bertujuan untuk menganalisis hasil penulisan refleksi dalam program medical writing presentation.

Metode: Penelitian ini merupakan penelitian deskriptif-eksploratif dengan pendekatan kualitatif. Subyek penelitian terdiri atas 207 mahasiswa kedokteran semester satu angkatan 2012. Data kualitatif didapatkan dari refleksi tertulis mahasiswa mengenai pengalaman belajar mahasiswa selama program MWP. Analisa kualitatif menggunakan content analysis melalui tahap identifikasi, koding, kategorisasi dan sintesis.

Hasil: Mahasiswa merasakan manfaat Zotero ${ }^{\circledR}$ sebagai program referensi dalam pembuatan karya tulis. Pembelajaran Zotero ${ }^{\circledR}$ dengan Pasukan Volunteer Zotero ${ }^{\circledR}$, mahasiswa merasa lebih nyaman dalam pembelajarannya. Teknik EBM yang diajarkan membantu mahasiswa mencari dan merangkum literatur-literatur. Mahasiswa juga secara tidak langsung mempelajari keterampilan soft skills seperti bekerja dalam kelompok, pengaturan waktu, dan membaca jurnal dalam Bahasa Inggris.
\end{abstract}

Korespondensi: kyky707@gmail.com 
Kesimpulan: Mahasiswa memiliki persepsi positif terhadap program MWP dan implementasinya. Mahasiswa memahami pentingnya program tersebut dan merasa keterampilan yang dipelajari dapat diimplementasikan secara langsung dalam karir akademik mereka. Walaupun mahasiswa menghadapi berbagai kesulitan dalam program MWP, mahasiswa mampu mengatasi kesulitan yang ada dan mempelajari keterampilan yang penting bagi pembelajaran di masa depan mereka.

KATA KUNCI: early EBM, persepsi, refleksi, medical writing, presentasi

\section{PENDAHULUAN}

Prinsip-prinsip dalam Evidence-Based Medicine (EBM) harus dikuasai oleh para penulis literature medis agar dapat menulis suatu literatur yang berkualitas dan orisinil. Prinsip EBM berguna untuk mendapatkan informasi yang terbaru, relevan dan akurat mengenai topik yang dibahas. Secara teknik, penulis juga perlu menguasai tata cara penulisan ilmiah di antaranya penulisan bibliografi. Penulisan bibliografi telah sangat terbantu dengan program-program referensi. Piranti lunak pengelola referensi (reference manager) berguna untuk memudahkan penulis melakukan penulisan referensi dari literatur-literatur yang digunakan-nya dalam penulisan ilmiah. Salah satu program pengelola bibliografi yang tersedia secara tak berbayar adalah Zotero ${ }^{\circledR}$.

Sebagai bagian komunitas ilmiah bidang kesehatan dan kedokteran yang berkontribusi besar terhadap penulisan literatur medis, mahasiswa kedokteran perlu dididik dan dilatih untuk menguasai prinsip-prinsip EBM dan teknik penulisan serta presentasi ilmiah. Oleh karena itu fakultas kedokteran perlu memberikan pendidikan kepada mahasiswanya supaya dapat menguasai hal-hal tersebut dalam kegiatan belajar-mengajar. Selain menumbuhkan cara berpikir kritis berdasarkan fakta pada mahasiswa kedokteran, EBM juga menjadi keterampilan yang berguna dalam penulisan literatur medis di kalangan mahasiswa kedokteran.

Keterampilan yang penting ini haruslah dikuasai oleh mahasiswa kedokteran secara bertahap sejak awal pendidikan kedokterannya, keterampilan ini harus diterapkan untuk mencari sumber informasi yang akurat dan dapat dipertanggungjawabkan. Fakultas Kedokteran Universitas Katolik Indonesia Atma Jaya (FKUAJ) pada tahun 2012, EBM mulai diajarkan kepada mahasiswa baru pada blok pertama semester satu (Blok Ilmu
Pengetahuan Dasar Kedokteran - IPDK) sebagai bagian dari topik Medical Writing and Presentation (MWP).

\section{Early EBM}

Evidence Based Medicine adalah proses meninjau secara sistematis, menilai dan menggunakan temuan penelitian klinis untuk membantu pemberian perawatan klinis yang optimal bagi pasien. ${ }^{1}$ EBM bertujuan untuk mengetahui tingkat kepercayaan dari bukti yang ada serta keuntungan dan kerugian dari suatu tindakan (dan tanpa suatu tindakan) dan diagnosa.

Pada umumnya EBM baru mulai diajarkan kepada mahasiswa setelah memasuki tahap klinik untuk menentukan diagnosis, terapi dan prognosis pasien yang dihadapi di rumah sakit. ${ }^{2}$ Namun seiring dengan timbulnya keluhan bahwa mahasiswa yang memasuki tahap klinik belum menguasai prinsip dasar EBM, dirasakan perlu untuk mengajarkan kepada mahasiswa pre-klinik materi EBM. ${ }^{3}$ Beberapa fakultas kedokteran di berbagai negara mengimplementasikan pembelajaran EBM kepada mahasiswa pre-klinik dimulai dari tahun pertama. $^{3,4}$

Penelitian lain membuktikan bahwa pemberian materi EBM di tahap awal pembelajaran mahasiswa kedokteran dapat dilakukan, praktis dan diinginkan oleh mahasiswa. Dengan demikian, dapat disimpulkan bahwa kurangnya pengetahuan klinis mahasiswa baru tidak menjadi hambatan untuk mempelajari EBM. 5,6

\section{Pandangan mahasiswa dan fasilitator terhadap early EBM}

Respon mahasiswa dan fasilitator terhadap program early EBM yang dilaksanakan di berbagai fakultas kedokteran di dunia pada umumnya positif. Mahasiswa menyatakan bahwa mereka menyukai pembelajaran EBM dan tertarik untuk terus mempelajari EBM serta mengaplikasikannya dalam pembelajaran di bidang kedokteran. Materi yang 
diberikan juga dirasa sesuai dengan tingkat pendidikan yang mereka tempuh. ${ }^{5,6}$

Menurut penelitian Srinivasan ${ }^{5}$, fasilitator merasa materi EBM perlu diajarkan kepada mahasiswa kedokteran tahun pertama. Fasilitator merasa tidak ada perbedaan mengajar EBM kepada residen dan mahasiswa, hal ini menunjukkan pembelajaran EBM tidak berbanding lurus dengan tingkat pengetahuan klinis yang dimiliki mahasiswa. Fasilitator EBM menyatakan mahasiswa mempersiapkan diri dengan baik sebelum sesi, tertarik mempelajari EBM, berpartisipasi dalam pembelajaran EBM dan menunjukkan rasa tanggung jawab dalam pembelajaran. ${ }^{5}$

Penelitian mengenai EBM sering dilakukan dengan metode studi kualitatif, karena studi kualitatif memberi pemahaman lebih lanjut mengapa suatu intervensi dapat bekerja dengan baik, meningkatkan akurasi dan relevansi dari studi kuantitatif yang ada, mengidentifikasikan variabel yang sesuai untuk diukur, menjelaskan hasil yang tidak terduga dan menghasilkan hipotesis dari studi kuantitatif. ${ }^{7}$ Studi kualitatif dapat merekam tidak saja pendapat fasilitator atau pendesain pembelajaran tetapi juga pendapat mahasiswa secara eksploratif. Salah satu cara mendapatkan persepsi mahasiswa setelah proses pembelajaran adalah dengan refleksi.

\section{Refleksi pembelajaran}

Masyarakat mengharapkan para pekerja profesional dapat melakukan pekerjaannya dengan aman dan etis, memiliki pengetahuan dan keterampilan yang terbaru serta mempunyai strategi untuk mencapai tujuan tersebut. Oleh karena itu, diperlukan self-regulation, self-assessment dan self-monitoring untuk mencapai harapan tersebut. Selfregulation mencangkup kemampuan untuk melakukan refleksi terhadap performa diri sendiri. ${ }^{8}$ Sebagai keterampilan yang penting dikuasai oleh pekerja profesional, maka proses refleksi semakin luas dipergunakan dalam berbagai bidang. Proses refleksi sendiri dapat dilakukan dengan reflective writting.

Reflective writting memiliki fokus terhadap pengalaman pembelajaran penulisnya termasuk ketika berusaha mengidentifikasi dampak dan arti dari pengalaman diri dan sekitarnya. ${ }^{9}$ Refleksi yang baik melibatkan: proses pemeriksaan secara kritis yang berkaitan dengan pengujian logika saat penarikan makna atau kesimpulan, proses analisis dari berbagai sudut pandang, serta proses berpikir kritis.

Refleksi diawali dengan memahami tujuan suatu aktivitas. Berdasarkan tujuan yang ingin dicapai, subyek melakukan observasi terhadap masalah yang ingin diselidiki. Setelah observasi awal, pada umumnya akan terdapat informasi tambahan mengenai masalah yang diselidiki. Kemudian, proses refleksi yang sebenarnya dimulai dengan meninjau ulang observasi awal, sehingga refleksi dapat diperkaya dengan sudut pandang yang beragam. Hasil refleksi dapat memperlihatkan hal-hal yang telah dipelajari atau dipecahkan termasuk kemungkinan refleksi lebih lanjut. Proses refleksi kemudian berulang kembali seperti sebuah siklus.

Praktik penulisan refleksi dapat dilakukan dengan berbagai cara. Salah satunya, menulis refleksi yang kemudian dibahas dalam diskusi kelompok kecil. Contoh lain melalui blog yang difasilitasi oleh fasilitator. Tidak terdapat perbedaan hasil dari kedua cara tersebut. ${ }^{10}$ Penggunaan media sosial seperti facebook ${ }^{\circledR}$ dan twitter $^{\circledR}$ juga dapat memfasilitasi mahasiswa kedokteran dengan membentuk komunitas reflective practice. Komunitas tersebut memungkinkan mahasiswa berpikir secara kritis tentang dampak tindakan yang dilakukannya dalam menggunakan media sosial. ${ }^{11}$ Selain itu penggunaan Google Docs ${ }^{\circledR}$ dapat membantu mahasiswa melakukan refleksi dalam kelompok kecil di luar kelas belajar. ${ }^{12}$

Refleksi dapat membantu mahasiswa mengidentifikasi manfaat dari pembelajaran secara aktif, mempromosikan kesadaran diri dan profesionalisme. Selain itu, refleksi dapat mendorong mahasiswa untuk berdialog dengan instruktur, memfasilitasi berpikir kritis, mengklarifikasi hubungan teori dan praktek serta mengembangkan keterampilan menulis secara profesional. ${ }^{13}$

\section{METODE}

\section{Desain metode pembelajaran MWP}

Penelitian ini dimulai dengan desain metode pembelajaran early EBM dalam bentuk topik Medical Writing and Presentation (MWP) yang disatukan dengan blok pertama semester pertama di FKUAJ, yaitu blok Ilmu Pengetahuan Dasar Kedokteran (IPDK) pada semester ganjil tahun 2012/2013. Dalam program MWP mahasiswa mempelajari prinsip dasar EBM, penggunaan 


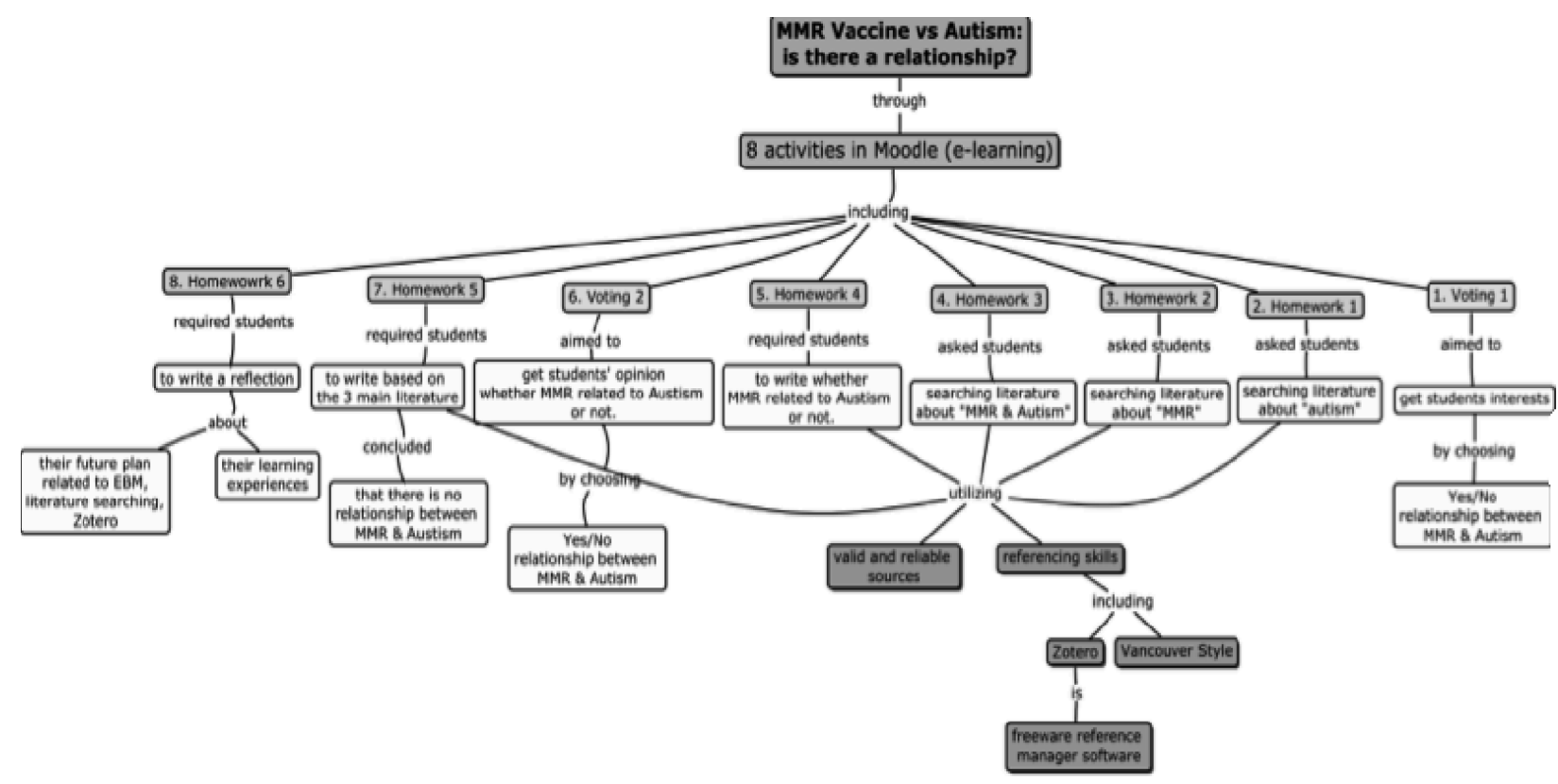

Gambar 1. Ringkasan desain pembelajaran MWP melalui Moodle ${ }^{\mathrm{TM}}$

Zotero $^{\circledR}$ sebagai program pengaturan referensi, dan Moodle ${ }^{\mathrm{TM}}$ sebagai media e-learning untuk pengumpulan tugas yang diberikan. Tujuan dari program MWP ini adalah memberikan edukasi kepada mahasiswa untuk menilai kesahihan sumber belajar mahasiswa kedokteran dan menyajikan presentasi ilmiah secara tertulis dan tatap muka dengan audiens teman sendiri. Keseluruhan penugasan dan penilaian MWP dilakukan melalui Moodle ${ }^{\mathrm{TM}}$, kecuali pada oral presentation yang dilakukan di depan kelas. Desain pembelajaran melalui Moodle ${ }^{\mathrm{TM}}$ dapat diringkas seperti Gambar 1.

Mahasiswa baru belajar mengenai EBM melalui platform Moodle $^{\mathrm{TM}}$. Mahasiswa mendapat tugas utama untuk mencari apakah terdapat hubungan antara vaksin MMR dan autisme. Pengambilan kesimpulan atas pertanyaan ini memerlukan penerapan prinsip-prinsip EBM. Rangkaian tugas ini dibagi menjadi delapan aktivitas dengan menggunakan Moodle ${ }^{\mathrm{TM}}$. Pertama, dilakukan voting kepada mahasiswa angkatan 2012 dengan pertanyaan apakah terdapat hubungan antara MMR (Measles Mumps Rubella) dan autism. Hasil dari voting ini menunjukkan 22\% mahasiswa menjawab bahwa terdapat hubungan antara MMR dan autisme. Mahasiswa kemudian diberikan tugas pertama untuk mencari literatur mengenai autisme, dengan tujuan memperkaya pengetahuan mahasiswa tentang masalah yang diteliti. Setelah itu mahasiswa mendapat tugas kedua untuk mencari literatur mengenai MMR. Tugas ketiga adalah mencari literatur mengenai MMR dan autisme. Pencarian literatur-literatur tersebut bertujuan untuk membuka pengetahuan mahasiswa mengenai hubungan MMR dan autisme. Mahasiswa kemudian diminta untuk menulis apakah MMR berhubungan dengan autisme. Pada keseluruhan penugasan tersebut, mahasiswa diminta menuliskan bibliografinya menurut gaya selikung Vancouver dengan bantuan piranti lunak pengelola referensi yang tak berbayar yaitu Zotero ${ }^{\circledR}$.

Dengan serangkaian tugas tersebut mahasiswa diharapkan sudah mempelajari ada atau tidaknya hubungan antara MMR dan autisme, kemudian dilakukan voting kedua dengan pertanyaan yang sama: apakah terdapat hubungan antara MMR dan autism? Dengan adanya voting sebelum dan setelah mengerjakan tugas diatas, diharapkan mahasiswa dapat menjawab pertanyaan voting kedua dengan benar. Hasil dari voting ini hanya $2 \%$ mahasiswa menjawab MMR berhubungan dengan autisme. Voting kedua ini bertujuan untuk mengetahui apakah EBM dapat membantu mahasiswa dalam belajar ilmu kedokteran. 
Dalam tugas yang kelima, mahasiswa diminta untuk menulis berdasarkan tiga literatur utama yang sesungguhnya menyatakan bahwa tidak ada hubungan antara MMR dan autisme. Ketiga literatur utama tersebut adalah:

1. Wakefield A, Murch S, Anthony A, Linnell J, Casson D, Malik M, et al. Retracted: Ileallymphoid-nodular hyperplasia, non-specific colitis, and pervasive developmental disorder in children. Lancet. 1998;351(9103):637-41.

2. Allan GM, Ivers N. The autism-vaccine story: fiction and deception? Can Fam Physician. 2010; 56(10):1013-1013.

3. Madsen KM, Hviid A, Vestergaard M, Schendel D, Wohlfahrt J, Thorsen P, et al. A populationbased study of measles, mumps, and rubella vaccination and autism. New Engl J Med. 2002; 347(19):1477-82.

Tujuan dari tugas kelima ini melatih mahasiswa untuk menggunakan sumber yang valid dan dapat diandalkan dalam pencarian literatur. Ketiga literatur utama tersebut adalah jurnal yang sudah diterbitkan, namun satu dari tiga literatur di atas merupakan jurnal yang sudah ditarik oleh Lancet. Pengalaman melihat sendiri jurnal yang terbit di Lancet tetapi ditarik kembali tentu diharapkan menjadi pembelajaran untuk mahasiswa, bahwa penulisan ilmiah membutuhkan bukti-bukti yang sahih.

Pada tugas terakhir, mahasiswa angkatan 2012 diminta menuliskan refleksi tentang pengalaman mereka mengerjakan tugasnya dan rencana mereka untuk pembelajaran selanjutnya mengenai EBM, pencarian literatur dan penggunaan Zotero sebagai program pengelola referensi.

Dalam mengerjakan tugas-tugas di atas mahasiswa menggunakan keterampilan yang diajarkan dalam program MWP, yaitu penggunaan sumber yang sahih, pencarian sumber dengan search engine sumber ilmiah, penggunaan AtmaLib dan penulisan referensi menggunakan Zotero $^{\circledR}$. Dalam penggunaan program manajemen referensi Zotero $^{\circledR}$, mahasiswa juga dapat meminta bantuan dari para senior mereka yang secara sukarela membantu, yang tergabung sebagai Pasukan Volunteer Zotero $^{\circledR}$ (PVZ). Mahasiswa dapat menanyakan cara penggunaan Zotero ${ }^{\circledR}$ dan meminta bantuan dari PVZ untuk mengatasi kesulitan-kesulitan teknis. Anggota PVZ adalah 23 mahasiswa angkatan 2009, 2010 dan 2011 yang telah terbiasa dengan Zotero dan direkrut secara sukarela. Diharapkan dengan adanya PVZ, mahasiswa dapat menguasai penggunaan Zotero sebagai program referensi.

Penggunaan Moodle ${ }^{\mathrm{TM}}$ sebagai media e-learning membantu mahasiswa mengerjakan tugas dalam waktu yang singkat tanpa perlu mengumpulkan tugas dalam bentuk hardcopy. Cara pengumpulan maupun mengunduh tugas ini diharapkan efektif dan efisien sehingga dapat menunjang pembelajaran mahasiswa di masa depan.

Respon mahasiswa terhadap program MWP yang dijalankan selama 5 minggu dapat dianalisa melalui refleksi yang ditulis mahasiswa dalam aktivitas terakhir MWP. Refleksi tersebut berisi pengalaman dan pandangan mahasiswa 2012 terhadap program MWP.

\section{Desain penelitian kualitatif}

Sumber data penelitian kualitatif berasal dari data teks refleksi mahasiswa diakhir program MWP yang terekam didalam Moodle ${ }^{\mathrm{TM}}$. Hasil tulisan mahasiswa dihapus nama dan NIMnya untuk menghindari bias pada penelitian, selanjutnya diganti dengan kode. Peneliti kemudian melakukan konten analisis dengan mengkategorikan isi refleksi responden. Pertama peneliti membaca 30 hasil refleksi responden untuk mengetahui berbagai kategori yang dapat dibuat. Kemudian peneliti melakukan inter-rater meeting untuk menentukan kategori yang akan dijadikan bahan analisis penelitian. Kategori yang sudah disetujui tersebut kemudian dimasukkan ke bentuk tabel dan disertai dengan kutipan refleksi responden.

Peneliti melakukan analisis terhadap data yang sudah dikategorikan tersebut. Untuk triangulasi, data tersebut dihubungkan dengan data dari hasil evaluasi mahasiswa 2012 terhadap MWP dan evaluasi mahasiswa 2012 terhadap PVZ serta evaluasi diri anggota PVZ. Untuk menjamin dependability maka dilakukan audit trail oleh seorang peneliti yang terbiasa melakukan studi kualitatif. Peneliti ini diminta memeriksa seluruh data dan hasil coding analysis. Peneliti ini sebagai auditor kemudian mengeluarkan pernyataan dukungan keabsahan (validity) data jika menurut pandangannya agregat data dalam penelitian ini memang pantas menjadi sumber analisa. 


\section{HASIL DAN PEMBAHASAN}

Hasil content analysis dengan tema-tema yang muncul dari refleksi mahasiswa ditampilkan dalam gambar 2. Analisis dilakukan oleh dua inter-raters dengan tingkat kesetujuan sesudah inter-rater meeting sebesar 79.7\%. Angka terakhir diperoleh melalui diskusi dan perbaikan coding serta definisinya. Selanjutnya peneliti utama (KY) melakukan keseluruhan analisis berdasarkan coding yang telah disepakati.

\section{Persepsi mahasiswa terhadap Zotero $^{\circledR}$}

Persepsi mahasiswa terhadap program Zotero ${ }^{\circledR}$ pada umumnya bersifat positif, mahasiswa merasa terbantu dalam membuat bibliografi pada tugas-tugas dengan jumlah referensi yang banyak. Mahasiswa diuntungkan melalui penggunaan Zotero ${ }^{\circledR}$ sebagai program penulisan bibliografi melalui berbagai aspek. Zotero ${ }^{\circledR}$ yang dapat menuliskan bibliografi secara otomatis dirasakan oleh mahasiswa sebagai manfaat utama penggunaan program ini. Hal ini secara langsung mempercepat mahasiswa dalam pembuatan bibliogafi, walaupun mahasiswa masih harus mencari journal abbreviation dan menyesuaikan kekurangan dengan gaya selikung yang dikendaki pemberi tugas atau syarat format penulisan ilmiah.

"Selain itu, saya juga bisa menjadi lebih paham dalam menerapkan penggunaan zotero ${ }^{\circledR}$, sehingga jika saya nantinya ingin membuat daftar pustaka berdasarkan jumal ilmiah, saya tidak perlu lagi repot-repot mengetik daftar pustaka satu per satu." 102 [920-1160]

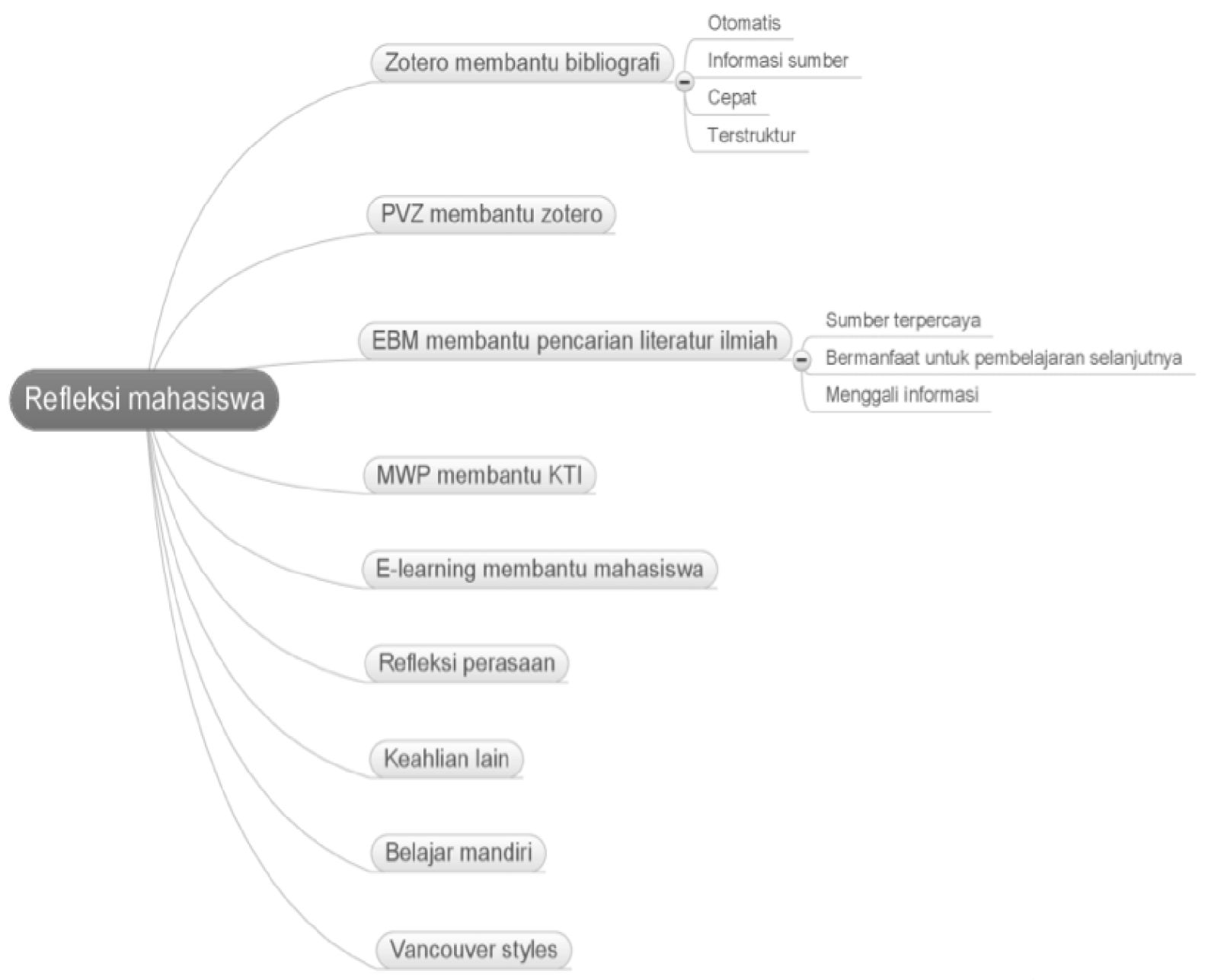

Gambar 2. Ringkasan tema hasil penelitian kualitatif 
"Hal-hal yang saya pelajari dari tugas-tugas ini antara lain adalah bagaimana membuat referensi yang baik dengan menggunakan bantuan program Zotero ${ }^{\circledR} . " 148$ [558-706]

Pada awalnya, mahasiswa mengalami berbagai kesulitan dalam mengoperasikan Zotero ${ }^{\circledR}$. Pemberian tugas mandiri sebagai salah satu aktivitas pembelajaran dipilih untuk membantu penguasaan mahasiswa terhada Zotero ${ }^{\circledR}$. Tugas mandiri berguna mendorong mahasiswa belajar hal baru secara bermakna. Penyelesaian tugas penulisan bibliografi menggunakan Zotero ${ }^{\circledR}$ memaksa mahasiswa untuk mau tidak mau belajar hal baru atau gagal sama sekali dalam seluruh rangkaian tugas. Setelah menguasai penggunaan Zotero ${ }^{\circledR}$, mahasiswa ingin terus menggunakan Zotero ${ }^{\circledR}$ untuk membantu mengerjakan tugas-tugas yang akan dihadapi saat menjalankan perkuliahan.

\section{Persepsi Mahasiswa terhadap Keberadaan PVZ}

Mahasiswa yang awalnya kesulitan menggunakan Zotero ${ }^{\circledR}$ merasa sangat terbantu oleh PVZ. Anggota PVZ mau secara sukarela membantu mahasiswa menangani masalah teknis yang berhubungan dengan penggunaan Zotero ${ }^{\circledR}$. PVZ membantu baik melalui forum tanya jawab secara online maupun melalui tatap muka dengan mahasiswa. Bantuan yang diberikan PVZ membantu mahasiswa menguasai penggunaan Zotero ${ }^{\circledR}$ dan memperkenalkan mahasiswa dengan kakak-kakak kelasnya.

Bantuan dari pihak yang lebih mampu (scaffolding) dalam hal ini PVZ menjadikan proses belajar lebih bermakna. Pada triangulasi data dengan hasil evaluasi terhadap PVZ maupun self-evaluation para anggota PVZ, kemaknaan yang sama juga diperoleh. Kedua belah pihak, mahasiswa yang dibantu dan yang membantu merasakan proses belajar yang bermakna. Mahasiswa yang dibantu oleh PVZ semakin mudah menguasai Zotero ${ }^{\circledR}$ selain itu juga terjadi komunikasi intens dengan teman sebaya. Sementara itu, mahasiswa yang membantu, para anggota PVZ, merasakan proses belajar Zotero ${ }^{\circledR}$ dimanfaatkan dengan nyata dan aspek komunikasi dengan teman sebaya semakin intens.

"Jujur saja, awalnya saya tidak sepenuhnya mengerti cara penulisan daftar pustaka melalui program zotero ${ }^{\circledR}$, tapi saat saya mengulangi tugas saya yang salah, saya harus banyak bertanya pada teman-teman lain yang mengerti dan saya juga sangat terbantu dengan adanya kakakkakak dari PVZ sehingga sekarang saya lebih paham mengenai cara penulisan daftar pustaka melalui program zotero $^{\circledR}$.” 186 [486-827]

Hal ini selaras dengan penelitian serupa yang dilakukan di School of Medicine, Washington University. Hasil penelitian ini menunjukkan mahasiswa yang dibantu oleh kakak kelasnya merasa belajar dari seseorang yang berada dalam lingkup umur yang sama. Pendekatan ini cukup menyenangkan dan mahasiswa merasa cara ini seharusnya diintegrasikan ke dalam kurikulum. ${ }^{4,14}$

Melalui kuesioner yang disebarkan setelah program MWP berakhir, seluruh anggota PVZ berpendapat PVZ diperlukan dalam membantu mahasiswa belajar penggunaan Zotero ${ }^{\circledR}$. Mahasiswa menilai PVZ membantu dalam pembelajaran Zotero ${ }^{\circledR}$ dengan skor rata-rata 7.79 dari 10. Refleksi mahasiswa juga menunjukkan pentingnya peran PVZ dalam proses pembelajaran di program MWP, sehingga PVZ dirasakan perlu dilanjutkan dalam program terus menerus.

\section{Persepsi Mahasiswa terhadap Teknik EBM}

Mahasiswa mendefinisikan EBM sebagai penghubung antara bukti-bukti ilmiah dan keputusan medis. Mayoritas mahasiswa merasa perlunya integrasi bukti-bukti ilmiah dalam pembelajaran, baik sebagai mahasiswa maupun kelak sebagai klinisi. ${ }^{15}$ Teknik EBM yang diajarkan kepada mahasiswa dalam program MWP mencakup pengertian literatur primer dan sekunder, pencarian sumber literatur terbaru yang dapat dipertanggungjawabkan dan keterampilan mengerti dan merangkum suatu artikel. Teknik early EBM yang diajarkan dalam program MWP membantu mahasiswa mencari dan menyeleksi literatur-literatur yang diakui keabsahannya dalam bidang kedokteran.

"Namun saya perlu mengingat bahwa tidak semua sumber dapat dipercaya kebenarannya, sehingga saya harus selektif dalam memilih sumber, dan dengan adanya tugas ini, saya merasa sangat terbantu dalam memilih sumber-sumber yang benar dan sahih." 119 [2369-2609]

Penelitian di Isfahan University of Medical Sciences menunjukkan bahwa workshop EBM untuk mahasiswa kedokteran tahap pre-klinik mampu meningkatkan kemampuan mahasiswa untuk membuat pertanyaan 
klinis dan mencari literatur yang sesuai. Hal tersebut juga merangsang mahasiswa untuk belajar dan mengaplikasikan EBM. ${ }^{15,16}$ Hal ini juga ditemukan dalam refleksi, mahasiswa menerapkan prinsip-prinsip EBM yang sudah dipelajari saat mengerjakan tugas dalam program MWP. Tak pelak lagi, pengalaman early EBM dapat dijadikan modal bagi mahasiswa dalam melanjutkan studinya.

"Menurut saya tugas yang diberikan ini sangatlah berguna bagi kami, mahasiswa/i kedokteran, untuk pembelajaran kami ke depan. Tugas-tugas berikutnya pasti dibutuhkan untuk mencari literatur, dan jika sudah menjadi dokter, dalam menggunakan sistem EBM, pencarian literatur sangatlah berguna. Untuk hari kedepan, saya akan giat mencari literatur agar dapat menambah pengetahuan serta untuk menyelesaikan tugas tertentu. Saya juga akan menggunakan program Zotero ${ }^{\circledR}$ dalam pembuatan daftar pustaka karena program tersebut sangatlah mempermudah." 166 [1729-2265]

Workshop dan kursus EBM juga meningkatkan rasa percaya diri mahasiswa akan kemampuannya mengaplikasikan teknik EBM. ${ }^{16}$ Dalam program MWP yang berjalan selama 5 minggu, mahasiswa dapat belajar early EBM dan keterampilan lainnya dengan baik. Hal ini mirip dengan penelitian di Taiwan yang menyatakan pembelajaran EBM selama 2 minggu saja dapat meningkatkan pengetahuan dan sikap mahasiswa terhadap EBM. ${ }^{17}$ Hasil penelitian menunjukkan mayoritas mahasiswa senang belajar EBM dan merasa bahan yang diajarkan sesuai dengan tingkat pembelajaran mereka dan berhubungan dengan ilmu klinis. ${ }^{18} \mathrm{Hal}$ ini juga ditemukan pada refleksi mahasiswa yang juga menyatakan pentingnya pembelajaran EBM dalam menunjang pembelajaran kedokteran dan akan menggunakannya dalam proses pembelajaran seperti PBL dan pengerjaan tugas ilmiah.

\section{Persepsi mahasiswa terhadap program MWP}

Refleksi mahasiswa menyimpulkan secara keseluruhan mahasiswa menyadari pentingnya program MWP sebagai modal keterampilan yang akan dibutuhkan di dunia medis. Walaupun awalnya mahasiswa mengeluh karena banyaknya tugas serta terbatasnya waktu untuk mengerja- kan tugas-tugas yang diberikan, setelah program MWP selesai, mahasiswa merasakan dampak serta kegunaan ilmu-ilmu yang sudah dipelajari untuk pembelajaran di fakultas kedokteran.

"Dari segi materi, pertama aku belajar mengenai penulisan daftar pustaka dengan Zotero ${ }^{\circledR}$ dan Vancouver Style. Belajar Zotero ${ }^{\circledR}$ dan Vancouver Style ini akan sangat membantu dalam studiku sebagai mahasiswa kedokteran, terutama dalam penulisan KTI dan penulisan referensireferensi dalam tugastugas yang diberikan." 12 [773-1078] "Cara pembelajaran ini berguna bagi saya dan akan saya terapkan dalam setiap tugas yang akan saya dapatkan dan juga dalam pembuatan KTI. Saya akan lebih cermat memilih sumber-sumberyang sah dalam pembuatan tugastugas saya berikutnya, memahami isi dan dapat mengambil kesimpulan dari sumber yang sah tersebut dan tidak lupa mencantumkan daftar pustaka yang baik dan benar dengan bantuan Zotero ${ }^{\circledR}$." 157 [1911-2311]

Refleksi dapat digunakan untuk membantu mahasiswa menghadapi kebingungan dalam proses pembelajaran dan mampu membuat pengalaman menjadi meaningful. ${ }^{19}$ Interaksi antar mahasiswa juga meningkatkan tingkat kepuasan mahasiswa terhadap pembelajaran. ${ }^{20}$

"Meskipun tugas-tugas yang diberikan Ibu Beth cukup banyak, namun saya merasa bahwa tugas-tugas itu semua akan ada manfaatnya di masa depan. Saya memang terkadang merasa lelah sekali dengan tugas yang tidak henti-hentinya, namun saya sadar bahwa semua itu adalah untuk kepentingan saya sendiri. Terimakasih ya Ibu Beth karena telah memberikan tugas-tugas dan pelajaran berharga." 148 [2138-2518]

Meaningful learning menurut Mayer adalah penggunaan keterampilan yang dimiliki untuk memecahkan masalah yang dihadapi. ${ }^{21}$ Dalam program MWP, keterampilan EBM yang diajarkan dapat secara langsung diaplikasikan mahasiswa saat mengerjakan tugas-tugas yang diberikan. Tugas-tugas ini telah menuntut mahasiswa berkarya dengan sepenuh hati. Tugas kemudian ditutup dengan refleksi untuk melihat kembali karya mahasiswa dan menyatakan rencana kegunaan hasil belajarnya di masa yang akan datang. Rangkaian tugas ini dengan demikian mendukung proses meaningful learning. 


\section{Teknik EBM mempersiapkan mahasiswa memasuki pembelajaran kedokteran}

Dalam mengerjakan tugas-tugas MWP, mahasiswa dituntut untuk mencari literatur yang dibutuhkan untuk mengerjakan tugasnya. Melalui pengerjaan tugas tersebut mahasiswa menjadi terbiasa membaca jurnal-jurnal ilmiah.

"Banyak hal yang dapat saya pelajari dari tugas-tugas yang diberikan oleh Ibu Beth. Pertama, saya belajar untuk membiasakan diri membaca dan memahami jurnal yang berbahasa Inggris." 36 [555-734]

Dalam penelitian Ilic dan Forbes di Monash University ${ }^{15}$ mahasiswa menyatakan bahwa EBM menjadi keterampilan yang berguna untuk melengkapi proses pembelajaran mereka. Keterampilan tersebut antara lain kemampuan untuk mencari literatur medis dengan lebih efektif dan relevan, serta mengaplikasikannya untuk memilih intervensi dengan alasan yang kuat. Dalam program MWP diajarkan perbedaan literatur primer dan sekunder, mencari literatur medis yang dapat dipertanggungjawabkan dan merangkum isi artikel. Keterampilan ini sangat penting dan berguna terutama dalam kegiatan PBL, mahasiswa dapat menerapkan prinsip EBM dalam pencarian literatur yang relevan dengan kasus. Kegunaan EBM untuk pencarian literatur yang berhubungan dengan kasus PBL diperkuat oleh penelitian di Monash University. ${ }^{15}$

Mahasiswa juga menyadari bahwa mereka belum memiliki pengalaman klinis, namun mahasiswa berencana untuk menggunakan keterampilan EBM saat memasuki tahap klinik dan merasa hal tersebut mampu mempengaruhi proses pengambilan keputusan. Melalui refleksinya, mahasiswa percaya bahwa keterampilan mengaplikasikan teknik EBM sangat penting bagi mahasiswa kedokteran dan mereka akan menerapkannya dalam pembelajaran.

\section{Persepsi mahasiswa terhadap pembelajaran dengan e-learning}

Mahasiswa merasa penggunaan Moodle ${ }^{\mathrm{TM}}$ dalam pemberian dan pengumpulan tugas antara dosen dan mahasiswa menjadi lebih efektif dan menarik. Mahasiswa dipermudah untuk melihat dan mengerjakan tugas tanpa harus bertatap muka dengan dosen.
"Lalu memudahkan saya sebagai mahasiswa kedokteran Atma Jaya untuk melihat adanya tugas dari para dosen dan mengumpulkannya hanya dengan membuka Moodle ${ }^{\mathrm{TM}}$ dari komputer pribadi." 193 [2350-2526]

Lau dan Bates melalui penelitiannya menyimpulkan bahwa pembelajaran secara e-learning lebih efektif dan dapat meningkatkan skor mahasiswa daripada metode tradisional untuk membantu pembelajaran dan menyamakan persepsi mahasiswa. ${ }^{18,22}$ Sebagai tambahan, prinsip go green juga dipraktikkan oleh mahasiswa dengan mengerjakan tugas dan mengumpulkannya secara daring. Modul e-learning yang tersedia juga dapat digunakan sebagai media komunikasi bagi mahasiswa dan dosen. ${ }^{17}$ Forum tanya jawab dirasakan efektif walaupun beberapa mahasiswa masih enggan untuk menggunakannya. Hal ini dapat dikarenakan mahasiswa merasa lebih nyaman berinteraksi secara tatap muka dengan teman maupun dosen, atau dengan menggunakan media komunikasi lainnya seperti blackberry messenger maupun pesan singkat. Sejalan dengan literatur hasil penelitian tersebut di atas, pembelajaran MWP dengan cara ini disukai mahasiswa dan dirasakan lebih efektif daripada metode tradisional.

\section{Mahasiswa belajar berbagai keahlian diluar tujuan utama program MWP}

Sebagai calon praktisi kesehatan selain mempelajari ilmu yang berhubungan dengan bidang kedokteran, mahasiswa juga perlu mempelajari berbagai keterampilan yang dibutuhkan seorang dokter. Dengan adanya tugas kelompok dalam program MWP mahasiswa belajar untuk berdiskusi dengan teman dan bekerja sebagai tim, mahasiswa bertukar ilmu dan saling membantu sehingga mempererat hubungan antar teman. Penelitian menunjukkan bahwa pembelajaran dalam kelompok kecil tidak hanya mengingkatkan minat mahasiswa tapi juga merangsang mahasiswa untuk berpikir kritis. Selain itu pada kelompok kecil mahasiswa dapat mengingat informasi lebih lama dan berpikir dalam taraf yang lebih tinggi daripada belajar secara individual. ${ }^{23}$

"Dalam proses pembelajaran ini, aku mendapat 1 pelajaran berharga dimana kita sebagai mahasiswa kedokteran pasti membutuhkan teman untuk berdiskusi dan bertukar pikiran. Bila kita sedang menghadapi kesulitan atau masalah dalam perkuliahan, kita dapat berbagi cerita 
bersama mereka karena mereka juga mahasiswa kedokteran yang mengerti kesulitan yang sedang kita hadapi. Dengan pertemanan ini, kita pun dapat saling mendukung dan menguatkan satu sama lain. Demikian juga tugas ini, dalam kelompok kita harus saling membantu satu sama lain, kita mau membagi ilmu yang kita dapat dengan mereka yang belum mengerti sehingga tugas ini pun dapat terselesaikan dengan baik." 18 [971-1637]

Dalam program MWP, mahasiswa juga belajar untuk mengatur waktu mereka dalam kehidupan di fakultas kedokteran. Adanya batas waktu pengumpulan tugas membuat mahasiswa lebih menghargai waktu dan memanfaatkannya dengan efektif.

"Selain itu, seorang dokter perlu management waktu yang baik. Management waktu itulah yang juga aku pelajari melalui dateline tugas yang singkat dan mepet antara satu dan yang lainnya." 15 [1608-1793]

Penelitian di Universitas Midwestern menunjukkan bahwa mahasiswa dengan kemampuan mengatur waktu secara efektif memiliki tingkat stress akademik yang lebih rendah. ${ }^{24}$ Tugas-tugas MWP dalam program tahun ajaran 2012/2013 yang menjadi basis penelitian ini, juga melatih mahasiswa untuk membaca cepat artikel-artikel yang berhubungan dengan tugas yang dikerjakan, oleh karenanya mahasiswa menjadi terbiasa membaca jurnal kedokteran dan mengasah kemampuan Bahasa Inggris.

\section{Mahasiswa belajar secara mandiri}

Melalui program MWP mahasiswa berkesempatan untuk belajar secara mandiri, baik melalui tugas-tugas yang diberikan maupun keterampilan yang perlu dipelajari. Mahasiswa memahami pentingnya proses belajar mandiri dalam pembelajaran mereka di bidang kedokteran.

"Cara pembelajaran yang diterapkan pun berbasis e-learning dan merupakan proses belajar mandiri. Penerapan pembelajaran mandiri sangat dibutuhkan di FKUAJ mengingat peran dosen hanya sebagai fasilitator maka untuk dapat memperoleh ilmu yang lebih dan berkembang menjadi mahasiswa kedokteran diperlukan peran aktif mahasiswa dalam mencari bahan pembelajaran dan belajar mandiri. Jadi saya akan lebih mendalami pelajaran yang saya dapatkan dan belajar mandiri untuk menunjang prestasi saya ke depannya." 107 [1995-2493]
Pembelajaran kedokteran tidak dapat mengandalkan kegiatan perkuliahan saja, karena pengetahuan di bidang medis yang terus berubah dan diperbaharui. Oleh karena itu, mahasiswa memerlukan pengembangan rasa untuk bertanggung jawab dan menyusun pembelajarannya sendiri. Dengan demikian diharapkan saat sudah menjadi seorang dokter pembelajaran akan terus berlangsung tanpa kehadiran dosen. ${ }^{25}$ Mahasiswa sendiri dalam refleksinya merasa bahwa terbatasnya waktu perkuliahan mengharuskan mahasiswa untuk belajar secara aktif mencari informasi dan tidak mengandalkan kuliah sebagai satu-satunya sumber pembelajaran dan menganggap dosen sebagai fasilitator. Dalam pembelajaran kedokteran mahasiswa cenderung hanya menerima materi yang diberikan dosen sebagai bahan pembelajarannya, hal ini menyebabkan mahasiswa tidak tahu materi yang semestinya ia pelajari serta tujuan dari pembelajaran itu sendiri. Mahasiswa menjadi pasif dan lebih cepat melupakan materi yang menurutnya kurang berhubungan dengan bidang kedokteran. Dengan belajar mandiri, mahasiswa dapat mengerti tujuan pembelajarannya serta menyusun rencana belajarnya. ${ }^{25}$

\section{Perasaan mahasiswa dalam proses pembelajaran MWP}

Refleksi dikategorikan menjadi dua yaitu reflection on action dan reflection in action. Reflection on action berhubungan dengan berpikir kembali kepada suatu kejadian dan mengidentifikasi hal-hal yang sudah baik dan hal-hal yang dapat ditingkatkan. Sedangkan reflection in action berhubungan dengan berpikir tentang performa pada saat suatu kejadian berlangsung serta mengidentifikasi kelebihan dan kekurangan pada saat yang bersamaan. ${ }^{26}$ Refleksi yang dilakukan mahasiswa berupa refleksi on action terhadap proses pembelajaran pada program MWP. Proses assessment (refleksi) dapat digunakan untuk mengukur derajat pemahaman dalam pembelajaran. ${ }^{27}$

Proses pembelajaran tidak hanya terbatas menambah pengetahuan saja, namun juga cara pengetahuan baru tersebut diintegrasikan dengan pengetahuan yang sudah ada. Dalam proses belajar refleksi berguna untuk mahasiswa agar dapat mengklarifikasi pikiran dan memperdalam pemahaman mahasiswa terhadap informasi yang diterima. ${ }^{28}$ Refleksi juga membantu 
mahasiswa menghubungkan pikiran, perasaan, dan pengalaman yang terjadi saat proses pembelajaran. Refleksi yang sudah dilakukan akan lebih merangsang mahasiswa apabila dosen memberikan umpan balik yang diformulasikan dalam bentuk pertanyaan dengan kesan positif. $^{29}$

Pada saat diberikan tugas yang dirasakan asing oleh mahasiswa, mahasiswa merasa panik, stress dan bingung karena banyaknya tugas dan ketidaktahuan mahasiswa mengenai cara atau teknik mengerjakannya. Hal ini ditambahkan oleh ketidaktahuan mahasiswa tentang penggunaan program Zotero ${ }^{\circledR}$ maupun istilah Vancouver Style, serta keterbatasan waktu untuk mengerjakan tugastugas.

"Di awal masa studiku di FKUAJ, aku dikagetkan dengan banyaknya tugas yang diberikan oleh dosen-dosen pengajar, salah satunya tugas-tugas Medical Writing dari Bu Beth. Awalnya stress dan bingung karena tugasnya banyak dengan deadline pengumpulan yang berhimpitan. Namun, sebagai mahasiswa aku sadar, bahwa tugas-tugas yang diberikan memiliki tujuan baik agar dapat membantu kita dalam mengerti dan mengaplikasikan materi yang sedang dipelajari. Hal itulah yang sangat kurasakan, setelah mengerjakan tugas-tugas Bu Beth hingga PR 6 ini, di akhir semuanya bermakna." 12 [36-593]

Dalam proses pengerjaan tugas-tugas MWP mahasiswa semakin mahir dan dapat mengerjakan tugas-tugas yang diberikan dengan baik. Pada akhirnya, mahasiswa merasa berterima kasih karena tugas-tugas yang diberikan mempersiapkan mahasiswa dengan keterampilan yang akan dibutuhkan dalam proses pembelajaran di fakultas kedokteran. Dalam pembelajaran juga diperlukan suasana dan pengalaman yang mendukung mahasiswa untuk melakukan refleksi dan berpartisipasi dalam pembelajaran yang meaningful dengan kesadaran serta bertanggung jawab untuk mengatur dan memonitor pembelajarannya sendiri. ${ }^{27}$

\section{KESIMPULAN}

Penelitian ini bertujuan untuk mengetahui persepsi mahasiswa terhadap program Medical Writing Presentation (MWP) yang diadakan pada semester satu Fakultas Kedokteran Atma Jaya. Dari 207 tulisan refleksi mahasiswa dilakukan analisis menggunakan pendekatan kualitatif. Berikut adalah hasil penelitian: (1) Mahasiswa memiliki persepsi yang positif dalam mempelajari prinsip EBM, karena EBM membantu mahasiswa mencari literatur yang sahih dan mencari informasi didalamnya, (2) Mahasiswa berpendapat bahwa keterampilan yang dipelajari akan berguna dalam pembelajaran selanjutnya di fakultas kedokteran, (3) Mahasiswa memiliki persepsi positif terhadap penggunaan Zotero ${ }^{\circledR}$ sebagai program referensi dalam mengerjakan tugas dan mahasiswa memiliki persepsi positif terhadap PVZ yang membantu mahasiswa mempelajari Zotero ${ }^{\circledR}$, (4) Mahasiswa memiliki persepsi positif terhadap penggunaan e-learning sebagai media pengerjaan tugas-tugas yang diberikan, (5) Mahasiswa juga mempelajari keterampilan hidup seperti pengaturan waktu, bekerja dalam kelompok dan membaca literatur medis. Selama pembelajaran dalam program MWP mahasiswa menghadapi berbagai tantangan dan kesulitan, namun pada akhirnya mahasiswa merasa program MWP efektif dan diperlukan bagi mahasiswa kedokteran.

\section{UCAPAN TERIMAKASIH}

Terima kasih untuk mahasiswa FKUAJ angkatan 2012, Pasukan Volunteer Zotero ${ }^{\circledR}$ tahun ajaran 2012/2013, dan Dr. Soegianto Ali, M.Med.Sc.

\section{DAFTAR PUSTAKA}

1. Rosenberg W, Donald A. Evidence based medicine: an approach to clinical problem-solving. Brit Med J. 1995;310:1122-1126.

2. Wadland WC, Barry HC, Farquhar L, Holzman C, White A. Training medical students in evidence-based medicine: a community campus approach. Fam Med. 1999;31(10):703-8.

3. Jarmila P, Vladimir M, Dagmar K. Teaching EvidenceBased Medicine to undergraduate medical students: Information Specialists as Multi-Professional Team Members. European Social Fund. 2007;3 (4):49-51.

4. Josephson SA, Whelan AJ. A new first-year course designed and taught by a senior medical student. Acad Med. 2002;77(12 Pt 1):1207-11.

5. Srinivasan M, Weiner M, Breitfeld PP, Brahmi F, Dickerson KL, Weiner G. Early introduction of an Evidence-based Medicine course to preclinical medical students. J Gen Intern Med. 2002;17(1):58-65.

6. Taheri H, Mirmohamadsadeghi M, Adibi I, Ashorion V, Sadeghizade A, Adibi P. Evidence-based medicine (EBM) for undergraduate medical students. Ann. Acad Med. Singap. 2008;37(9):764-8. 
7. Popay J, Williams G. Qualitative research and evidence-based healthcare. J R Soc Med. 1998;91(Suppl 35):32-7.

8. Mann KV. Reflection: understanding its influence on practice. Med Educ. 2008;42(5):449-51.

9. Fink LD. Creating significant learning experiences: an integrated approach to designing college courses. John Wiley \& Sons; 2003.

10. Fischer MA, Haley H-L, Saarinen CL, Chretien KC. Comparison of blogged and written reflections in two medicine clerkships. Med Educ. 2011;45(2):166-75.

11. Brown AD. Social media: a new frontier in reflective practice. Med Educ. 2010;44(8):744-5.

12. George DR. Using Google Docs to enhance medical student reflection. Med Educ. 2012;46(5):504-5.

13. McGuire L, Lay K, Peters J. Pedagogy of reflective writing in professional education. Journal of the scholarship of teaching and learning. 2009;9(1):93107.

14. Capstick S, Fleming H. Peer assisted learning in an undergraduate hospitality course: second year students supporting first year students in group learning. Journal of Hospitality, Leisure, Sport \& Tourism Education [Internet]. 1(1). Available from: http://www.heacademy.ac.uk/assets/hlst/ documents/johlste/vol1no1/0001.pdf

15. Ilic D, Forbes K. Undergraduate medical student perceptions and use of Evidence Based Medicine: A qualitative study. BMC Med Educ. 2010;10(1):58.

16. Jamero DJ, Borghol A, Mihm L. comparison of computer-mediated learning and lecture-mediated learning for teaching pain management to pharmacy students. Am J Pharm Educ. 2009;73(1):5.

17. Abdelhai R, Yassin S, Ahmad MF, Fors UG. An elearning reproductive health module to support improved student learning and interaction: a prospective interventional study at a medical school in Egypt. BMC Med Educ. 2012;12(1):11.

18. Varghese J, Faith M, Jacob M. Impact of e-resources on learning in biochemistry: first-year medical students' perceptions. BMC Med Educ. 2012 ; 12(1):21
19. Hajar T, Maede M, Iman A, Vahid A, Atefe S, Peiman A. Evidence-based medicine (EBM) for under-graduate medical students. Ann Acad Med SG. 2008; 37.

20. Cheng HM, Guo FR, Hsu TF, Chuang SY. Two strategies to intensify evidence-based medicine education of undergraduate students: a randomised control trial. Ann Acad Med SG. 2012;41:4-11.

21. Mayer RE, Moreno R. Nine ways to reduce cognitive load in multimedia learning. Educ Psyc. 2003;38(1):43-52.

22. Lau F, Bates J. A review of e-learning practices for undergraduate medical education. J Med Syst. 2004;28(1):71-87.

23. Gokhale AA. Collaborative Learning enhances critical thinking. J Technol Educ. 1995;7(1).

24. Misra R, Mckean M. College students' academic stress and its relation to their anxiety, time management, and leisure satisfaction. Am J Health Studies. 2000;16(1).

25. R.L.B. N, D.A. P. Toward independent learning: curricular design for assisting students to learn how to learn. J Med Educ. 1981;56:886-93.

26. Grant J. Learning needs assessment: assessing the need. Brit Med J. 2002;324(7330):156-9.

27. Garrison DR. Cognitive presence for effective asynchronous online learning: the role of reflective inquiry, self-direction and metacognition. Available from: http://cguevara.commons.gc.cuny.edu/files/ 2009/09/Learning-Effectiveness-paper-Garrison.pdf

28. Ong R. The role of reflection in student learning: a study of its effectiveness in complementing problembased learning environments. [cited 2013 Sep 22]Available from: http://www.myrp.sg/ced/ research/papers/role_of_reflection_in_student_ learning.pdf

29. Dekker H, Schönrock-Adema J, Snoek JW, Molen T van der, Cohen-Schotanus J. Which characteristics of written feedback are perceived as stimulating students' reflective competence: an exploratory study. BMC Med Educ. 2013;13(1):94. 